\title{
Intersection of MicroRNA and Gene Regulatory Networks and their Implication in Cancer
}

\author{
Malik Yousef ${ }^{1}$, Hung V. Trinh ${ }^{2}$ and Jens Allmer ${ }^{3 *}$ \\ ${ }^{1}$ The College of Sakhnin, Sakhnin, Israel The Galilee Society Institute of Applied Research, ShefaAmr, Israel; \\ ${ }^{2}$ Retrovirus laboratory, Department of Molecular \& Comparative Pathobiology, School of Medicine, Johns Hopkins \\ University, 733 N. Broadway, Baltimore, MD 21205, USA; ${ }^{3}$ Molecular Biology and Genetics, Izmir Institute of \\ Technology, Urla, Izmir, Turkey
}

\begin{abstract}
MicroRNAs (miRNAs) have attracted heightened attention for their role as post-transcriptional regulators of gene expression. It has become clear that miRNAs can both up- and downregulate protein expression. According to current estimates, most human genes are harboring miRNAs and/or are regulated by them. Thus miRNAs form a complex network of expression regulation which tightly interacts with known gene regulatory networks. Similar to some transcription factors, some miRNAs can have hundreds of target transcripts whose expression they modulate. Thus miRNAs can form complex regulatory networks by themselves, but because their expression is often tightly coordinated with gene expression, they form an intertwined regulatory network with many possible interactions among gene and miRNA regulatory pathways. In this review we first consider gene regulatory networks. Then we discuss microRNAs and their implication in cancer and how they may form regulatory networks. Finally, we give our perspective and provide an outlook including the aspect of personalized medicine.
\end{abstract}

Keywords: Invasion, metastasis, microRNA, network, pathway, Petri nets, reconstruction, regulation, tumor suppression.

\section{INTRODUCTION}

MicroRNAs (miRNAs) are short ( 22 nts) nucleotide sequences that are usually co-transcribed during the production of mRNA. Some miRNAs, however, are organized in intergenic regions and are exclusively transcribed by RNA polymerase II. The pre-miRNAs set themselves apart from other RNAs by their characteristic stem loop (hairpin) structure which appears important for their recognition during biogenesis, the process of maturation leading to functioning mature miRNAs. This is a multistep process taking place partially in the nucleus and in the cytosol. For more details on biogenesis, see chapters in the book miRNomics: MicroRNA Biology and Computational Analysis edited by Allmer and Yousef (Methods in Molecular Biology, 2013).

MicroRNAs are potent regulators of protein expression. Although originally identified as negative post-transcriptional regulators of protein expression, since 2007 there has also been growing evidence for positive regulation of protein expression [1-4]. Gene regulation has long been known to be modulated in both directions and in retrospect it seems only logical that miRNAs should also be involved in both up and downregulation.

Since many miRNAs are co-transcribed with their source mRNAs, their expression levels correspond to each other. However, many additional regulation scenarios can apply to

*Address correspondence to this author at the Molecular Biology and Genetics, Izmir Institute of Technology, Urla, Izmir, Turkey;

E-mails: jens@allmer.de, jensallmer@iyte.edu.tr
miRNAs post-transcriptionally and thus lead to a deviation between gene expression and corresponding miRNA levels. Nonetheless, miRNAs, which are co-expressed with their source genes, may have a regulatory effect that is in-line, independent, contrary, or even self-directed when compared to the potential regulatory effect of the source gene (Fig. 1). Gene a (Fig. 1) harbors 4 miRNAs which are co-expressed with it. The miRNA miR- $a$ targets the parent gene and causes its post-transcriptional repression while also downregulating itself.

Another miRNA $(m i R-b)$ has, indirectly, the same effect on the target gene of its parent (Gene $b$ ) and the regulations are thus in-line with each other. The $m i R-c$ has the same direct effect on Gene $d$ as its parent and the regulation is therefore coordinated. The miRNA $m i R-d$ has two targets one of which is not regulated by its parent gene (independent) while the regulation of the other (Gene $b$ ) is contrary to the effect its parent exhibits. In summary, (Fig. 1) gives an overview of different ways gene regulation and miRNA regulation can be coordinated. This will be discussed in more detail in the section on Super Regulatory Networks.

It is known that gene or miRNA regulatory networks or any network in a cell do not exist in a void, but are interconnected and, if one is perturbed, all work together to compensate and to reestablish homeostasis [5]. This complexity is too vast to be covered here and therefore we will not detail protein interaction networks, signal transduction networks, or higher ecological views of networks. It is this complexity which imposes a great obstacle on pharmacogenomics, making accurate predictions of global side effects currently im- 


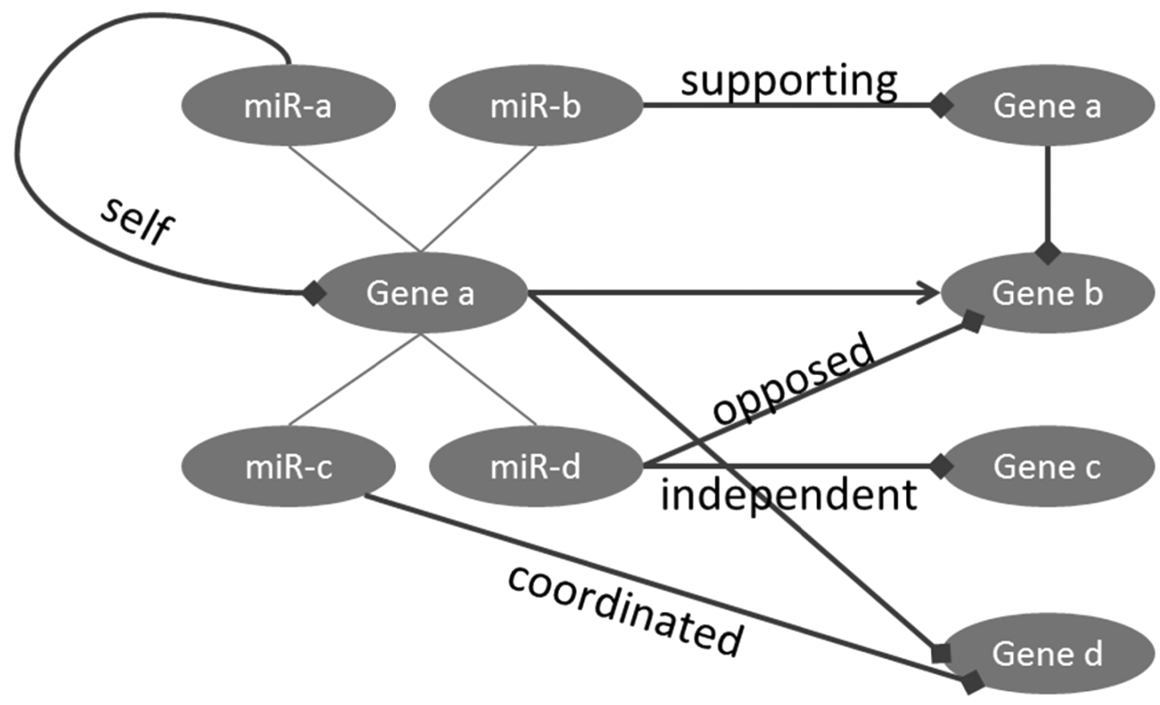

Fig. (1). MicroRNA and gene regulation can have different types of effects (self, opposed, independent) for miRNAs from the perspective of a source gene (Gene a). They can also have similar or supporting effects (supporting, coordinated) from the same perspective. Connections without arrows depict that the miRNAs derive from the same transcript. Arrows indicate upregulation and terminal diamonds depict downregulation.

possible since all interacting networks that contribute to the global system cannot currently be modeled. It has become clear that there is likely a role for all regions of a genome [6] and present modeling of regulation is probably imprecise since much information on regulation is still being uncovered.

As mentioned above, there are a wide range of networks in a cell, for example: Gene regulatory, signal transduction, metabolic, and protein-protein interaction networks. It is futile to discuss all these interrelated issues here and, therefore, the focus is on gene and miRNA regulatory networks as well as their intersection. In the following we will first outline gene regulatory networks as far as they intersect with microRNA regulatory networks.

\section{GENE REGULATORY NETWORKS}

The central dogma in molecular biology claimed that one gene leads to a single gene product [7]. With the discovery of alternative splicing, alternative start sites, and other modifications such as RNA editing, it is now agreed that a gene can have many products. Additionally, genes can have byproducts such as miRNAs. Genes cannot interact with other genes other than via their gene products or byproducts. For the purpose of this work, genes can be considered nodes in a graph with their products being edges if they lead to an interaction with other genes (Fig. 2). For example, Wu and colleagues showed that the same gene can lead to the production of pro- and anti-apoptotic factors due to alternative splicing (Fig. 2) [8].

\section{REGULATORY PATHWAYS}

A regulatory pathway in biology describes the interaction among genes within a biological system. Since genes do not interact directly, they do so via their products which are, for example, proteins and miRNAs. A regulatory pathway is often triggered through a stimulus like the binding of a ligand to a receptor protein which causes the protein to set off a cascade of interactions with other proteins. Among these proteins are transcription factors which modulate gene expression. This leads to an increase or decrease of protein levels expressed by the affected genes. The whole process aims to elicit a cellular response appropriate for dealing with the initial event of binding a specific molecule. All parts of these often large and complicated pathways are candidate targets for pharmaceuticals. The importance of the pathway is two-fold. On one hand, knowledge of the pathway allows selection of a target and generation of drugs to change it. On the other hand, such knowledge allows prediction of the effects of modulating a member of the pathway.

The Kyoto Encyclopedia of Genes and Genomes (KEGG) provides, among other services, pathway interaction maps (http:/www.genome.jp/kegg/pathway.html) and these represent how genes or their products perform metabolic processes [9, 10]. Since KEGG has been commercialized, other resources like Reactome [11] have been proposed to provide free access to pathway information. Reactome is not as comprehensive as KEGG, but we believe that with the current progress it will close the gap within the year 2014 . These pathway databases are necessary as references for modeling and also to place additional information such as miRNA regulation into the proper perspective.

\section{RECONSTRUCTION, VISUALIZATION, AND NET- WORK ANALYSIS/MODELING TOOLS}

The visualization of networks in biology is usually quite similar to models in mathematical graph theory where a graph $(G)$ is a set of vertices (V) connected by edges (E) such that $G=(V, E)$. Vertices can, for example, represent genes or miRNAs or any other biological entity; while edges often signify upregulation or downregulation or any other kind or interaction among nodes (for an example see Fig. 1). 


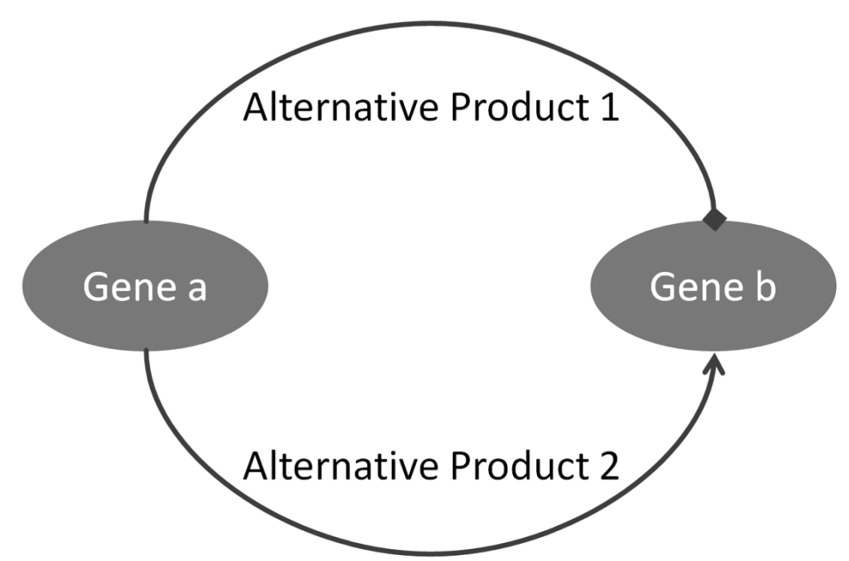

Fig. (2). Genes can be represented as nodes (ovals) and their interactions via gene products can be represented as edges. Multiple edges originating from one node represent alternative gene products. Alternative product one inhibits "Gene b" (diamond) whereas alternative product 2 activates it (arrow head).

Visualization of regulatory networks has been a hallmark of KEGG but today there are numerous software programs which allow the modeling of graphs $[12,13]$. Networks as described above are static. It is, however, important to allow for the application of mathematical models and for the intersection of different networks so that hypotheses can be tested. We believe that such software will become especially important in pharmacogenomics where they can help uncover side effects or point to new key players in the network to identify novel drug targets.

An extension of the simple network structure, that allows modeling and dynamics, are Petri nets which have two different types of vertices: one which represents a place (containing some amount of a compound) and another which represents a transition (how a compound is transformed or acted upon). Places and processes are connected by directed edges (showing how compounds can be transmitted among the places) under the rule that places may not be connected and processes may not be linked directly (Fig. 3).

Petri nets are usually used for modeling in systems biology, but they may also be used to simulate gene regulation (compare Fig. 1 and Fig. 3). To properly achieve that task, however, extensive measurements of gene, miRNA, and protein quantities are necessary to properly reconstruct even a small and simplified model as shown here.

Only a few of the software programs which offer graph visualization such as Cytoscape [14] also allow modeling using Petri nets [13]. We would like to highlight VANESA (http://vanesa.sourceforge.net/) here since it has many of the important features for network analysis such as Petri net modeling and a subscription to KEGG. In addition, we are currently working on the possibility of intersecting KEGG and miRNA regulatory networks so that the effect of miRNAs on other pathways and vice versa can be directly and visually investigated. Furthermore, VANESA allows the discovery of substructures (i.e. regulatory patterns) and the detection of hubs (i.e. key players in regulation).
The visualization, modeling, and analysis of graphs are important features, but network reconstruction may be the most important one because, only if a graph is successfully established, can it be analyzed in a meaningful manner. Some of the tools mentioned above (like VANESA), allow the reconstruction of networks with the aid of experimental data. Schlitt and Brazma caution, however, that the resulting networks are not equal and that, depending on their construction, they may fall into four categories [15]. These categories are: parts lists, topology models, control logic models, and dynamic models (the aforementioned Petri nets). They further argue that it is important to know the limitations of the model employed to not overrate its predictions.

\section{MICRORNA REGULATORY NETWORKS}

MicroRNAs or molecules mimicking them can potentially be used as drugs while, on the other end of the spectrum, they can be drug targets by using, for example, antisense RNA. One established application is their use as biomarkers for diagnostics [16]. MicroRNAs have also been tested as biomarkers in cancer [17]. Cancer is an important field of research and miRNAs have long played a role in cancer research. Satoh confirms that there are complex regulatory connections among proteins and miRNAs [18] and that this crosstalk is important in oncogenic signaling [19], especially for the E2F family proteins investigated in their studies $[18,19]$.

In the following we will discuss how miRNAs are involved in tumor suppression and, adversely, also in invasion and formation of metastases. This seemingly Janus-like quality of haing two opposite faces, is not surprising considering that it is not a miRNA which causes cancer but the perturbation of the overall network. Thus the same miRNA may potentially be upregulated in one cancer and downregulated in another.

\section{IMPLICATIONS IN CANCER}

Although it is well known that miRNAs regulate their targets, it is unclear how they do so cooperatively [20]. It has been shown; however, that a miRNA can regulate multiple targets and that one target can be regulated by multiple miRNAs. It could be speculated that one particular miRNA may partially downregulate some targets (although it may do so cooperatively with other miRNAs) while it could completely downregulate other targets. This opens the possibility to fine tune the regulation of protein expression using multiple, potentially overlapping sensory pathways. As difficult as it is to elucidate the role of a particular miRNA and its targets, much progress has been made and we will first discuss some results where miRNAs can act as tumor suppressors.

\section{A MICRORNA CAN ACT AS TUMOR SUPPRESSOR}

The roles of miRNAs in tumorigenesis, tumor invasion, and metastasis have been extensively described [21, 22]. The most well-known miRNAs involved in tumorigenesis are miR-15a, miR-16-1, let-7, the miR-29 family, the miR-17-92 cluster, miR-21, and miR-155. These miRNAs can act as tumor suppressors and, when their functions are lost, the transformation of normal cells into malignant cells may be triggered. The cause of function loss may derive from ge- 


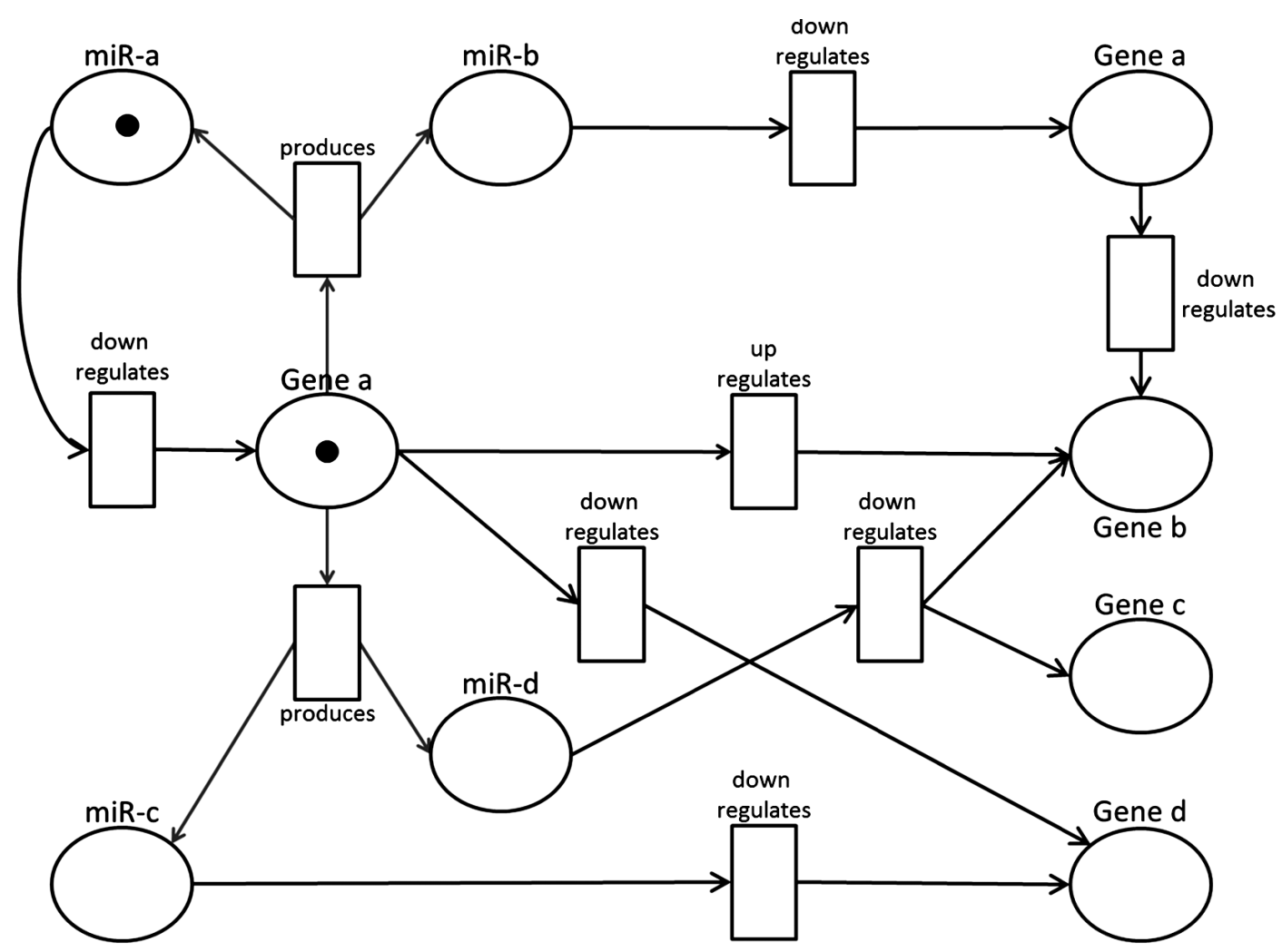

Fig. (3). The transformation of Fig. 1 into one of many possible Petri net representations. Places are indicated by circles and processes by rectangles. Black dots depict available compounds in a place. All places are modeled to be discrete and all transitions are assumed to be continuous (both assumptions would probably not hold in reality and the fig is only for instructional purposes).

nomic changes including deletion [23], other mutations, epigenetic silencing, and other alterations $[24,25]$. The miRNAs miR-15a and miR-16-1 were first observed with deletion or downregulation in chronic lymphocytic leukemia [23, 26]. The roles of these miRNAs have been further elucidated when an anti-apoptotic BCl-2 was found to be the target of these miRNAs [27, 28].

Another well-known miRNA family, let-7, was often found to be downregulated in tumors such as lung and breast cancer [29-31]. The let-7 family was found to target oncogenes including the RAS family [30,32], high mobility group A2 (HMGA2) [33], and MYC [34]. In lung cancer, expression of RAS and let-7 resulted in opposite patterns with low levels of let-7 and high levels of RAS in cancerous cells, while a high level of let-7 and a low level of RAS seems to be typical for normal cells [30]. let-7 also targets HMGA2 and the removal of HMGA's 3'UTR region resulted in HGMA2 overexpression and the induction of tumor formation [33]. Binding to the 3'UTR of an mRNA is a wellaccepted mode of action for a miRNA to regulate its target.

The miR-29 family consists of miRNAs, which form two clusters, miR-29b-1/miR-29a in chromosome locus 7q32 and mir-29b-2/miR-29c in chromosome locus 1q23. It has been shown that the chromosome locus $7 \mathrm{q} 32$ is frequently deleted in myelodysplasia acute myeloid leukemia [35]. In addition, the miR- 29 family members have been reported to be downregulated in chronic lymphocytic leukemia [26], lung [31] and breast cancer [29]. The miR-29 family members are known to target directly the myeloid leukemia cell differentiation protein (MCL-1), anti-apoptotic member of the Bcl-2 family of proteins [36], and the oncogene T-cell leukemia/lymphoma 1 (TCL-1) [37]. Taken together, these factors may well explain the tumor suppressor effect.

The well-studied microRNA cluster miR-17-92 contains seven homologous miRNAs and has been identified to have oncogenic potential. These miRNAs target multiple genes responsible for both proapoptotic pathways and oncogenic activities $[38,39]$. The oncogenic effects of the miR-17-92 cluster have been shown to lead to the acceleration of cMyc-induced lymphoma development in a mouse model [38]. Furthermore, Bim, PTEN, and p21proteins were identified as targets of this miRNA cluster [39, 40]. In contrast, under some circumstances, this miRNA cluster might act as a tumor suppressor as in the case of inhibition to abolish Myc-induced cell proliferation and miR-17-5p repressed proliferation of breast cancer cells $[41,42]$.

Unlike most other miRNAs which tend to be downregulated in cancer cells, miR-21 is generally upregulated in a variety of cancer types [43]. Knockdown of miR-21 induced activation of caspases resulting in apoptosis of glioblastoma cells [44], activation of the p53 pathway, mediation of TGF$\beta$ signaling induction, and eventual suppressed cell growth and increased apoptosis in glioblastoma cells [45]. In addition, knockdown of miR-21 also caused suppression of proliferation in HeLa cells [46]. Downregulation of miR-21 repressed cell growth in breast cancer cells through targeting 
the PDCD4 tumor suppressor [47]. Recently, many tumor suppressors including, but not limited to PTEN, PDCD4, Tropomyosin, and Sprouty 1 have been experimentally validated [48].

The miR-155 also displays oncogenic activity and has been described in various cancers such as blood and breast cancer [49]. The miR-155 was first reported in the oncogenesis of hematopoietic malignancies where it was found to be overexpressed in B-cell lymphomas and chronic lymphocytic leukemia [50]. Similarly, transgenic miR-155 in B-cells also resulted in acute lymphoblastic leukemia/high-grade lymphoma [51]. In breast cancer, the overexpression of miR155 was highly correlated with higher tumor grade and lymph node metastasis [52]. Treatment with a miR-155 antisense construct inhibited growth, induced cell arrest in G0/G1 phase, enhanced apoptosis, and increased radio sensitivity [52]. Furthermore, suppressor of cytokine signaling 1 (socs1), a tumor suppressor - a negative feedback regulator of Janus activated kinase (JAK)/signal transducer and activator of transcription (STAT) signaling [53], has been proposed to be a target of miR-155 in breast cancer cells [54]. It was further confirmed that the overexpression of miR-155 caused repression of soc1, which induced cell proliferation, colony formation, and xenograft tumor growth in breast cancer cells [54]. In addition, $\mathrm{miR}-155$ has also been found to be overexpressed in pancreatic [55, 56] and thyroid tumors [57].

As pointed out for the miR-17-92 cluster, miRNAs may present a dichotomy and may act as tumor suppressors or promote tumorigenesis, invasion, and metastasis.

\section{MICRORNAS CAN SUPPORT INVASION AND ME- TASTASIS PROCESSES}

Metastases are the main cause of cancer-related mortality. Metastasis begins when cells migrate from primary tumors to neighboring cells and invade the basement membrane. Recently, miRNAs have been shown to play critical roles in metastasis and the invasiveness of cancer cells [58], [59]. Although the oncogenic and tumor-suppressive roles of many miRNAs have been well characterized, the action of these miRNAs in mediating tumor metastasis have only recently been addressed [60] and still remain largely under investigated $[38,49]$. Among these, the most well characterized oncogenic miRNAs include miR-9, miR-10b, miR-107, miR-143, miR-151, miR-373, miR-375, and miR-520h.

The microRNA miR-9 acts as an oncogene or as a tumor suppressor [61]. It has been shown to be associated with the development of cancer metastasis [62-65]. However, silencing of miR-9 by cytosine-phosphate-guanine $(\mathrm{CpG})$ island hypermethylation was found in many tumors [29, 66], which indicates that miR-9 can also act as a tumor suppressor. When miR-9 is upregulated in breast cancer, it directly targets CDH1, the E-cadherin-encoding messenger RNA, leading to an increase of cell motility and invasiveness [62]. The downregulation of $\mathrm{CDH} 1$ triggers activation of $\beta$-catenin signaling which is then followed by activation of the vascular endothelial growth factor (VEGF), finally leading to increased tumor angiogenesis. In the non-metastasis model, overexpression of miR-9 caused development of pulmonary micrometastases in mice while inhibition of miR-9 had the opposite effect [62]. In addition, miR-9 also targets MYC and $\mathrm{MYCN}$ and the expression of $\mathrm{miR}-9 / \mathrm{MYC} / \mathrm{MYCN}$ is highly correlated with tumor grade and metastasis status [62]. Recently, miR-9 was found to target the suppressor of cytokine signaling 5 (SOCS5) [67]. Overexpression of miR9 caused a reduction of SOCS5, leading to activation of the JAK-STAT pathway and promotion of endothelial cell migration and tumor angiogenesis [67]. Treatment with antimiR-9 inhibitors suppressed cell migration in vitro and decreased tumor burden in vivo [67]. In summary, miR-9 plays a crucial role in activation of cell migration and tumor angiogenesis.

Another miRNA, miR-10b, has been described extensively in respect to metastasis formation. Indeed, its expression correlates with high-grade malignancy in various types of cancer. In fact, it is highly expressed in metastasis status [68], hepatocellular carcinomas from metastasis-positive patients [65], and in pancreatic adenocarcinomas [69]. In breast cancer, overexpression of miR-10b triggered the formation of metastasis and tumor invasion of a nonmetastatic human breast cancer cell line (SUM159 cells) and xenotransplantation models [60]. In addition, miR-10b also contributed to the progression of other types of cancer. For example, anti-miR-10b inhibitor caused reduction of cell proliferation, migration, and invasion in malignant peripheral nerve sheath tumor cells [70]. In esophageal cancer cells, overexpression of miR-10b increased cell motility and invasiveness, while inhibition of miR-10b reduced cell invasiveness [71]. Similar phenomena were observed with nude mice in nasopharyngeal carcinoma cells [72].

Unlike miR-10b, overexpression of miR-103/107 suppresses tumor angiogenesis, tumor growth, and tumor VEGF expression in mice with colon cancer [73]. Knockdown of endogenous miR-107 resulted in increasing HIF-1 $\beta$ expression and activation of hypoxic signaling, which is regulated by tumor suppressor gene TP53. More recently, miR$103 / 107$ have been found to target the known metastasis suppressors, death-associated protein kinase (DAPK) and Krüppel-like factor 4 (KLF4), in colorectal cancer cells [74]. In mouse models, overexpression of miR-103/107 caused reduction of DAPK and KLF4, leading to local invasion and liver metastasis effects, thus displaying the inverse correlation of DAPK/KLF4 and miR-103/107. This has also been observed in patients with metastasis status [74]. Similarly, high expression levels of miR-103/107 were associated with metastasis and poor outcome in breast cancer [75]. Another interesting discovery of the mechanism of miR-107 was its ability to negatively regulate tumor suppressor miRNA let-7 via direct interaction [76]. The miR-107 was highly expressed and its expression was reciprocal to expression of let-7 in both malignant tissues from patients and cell lines of breast cancer [76]. In contrast, the depletion of miR-107 caused overexpression of let-7 in human and mouse breast cell lines.

The miR-143 represents one of the best-characterized oncogenes. It is located in a fragile region of the chromosome, often found to be deleted and its expression tends to be lower in many different types of cancers such as colon and gastric cancers as well as in B-cell lymphoma [77-79]. Overexpression of miR-143 inhibits cell proliferation in several cancer cell lines $[80,81]$ and regulates contractile phe- 
notypes of murine vascular smooth muscle cells [82]. The oncogene KRAS was identified to be the target of miR-143 [83].

The miR-151 localizes within the intron 22 of FAK (focal adhesion kinase) and it was often found to be overexpressed in human tumors and to promote cancer cell invasion and metastasis formation [84]. Overexpression of miR-151$5 \mathrm{p}$ significantly enhanced cell migration and invasion in vitro and in vivo in hepatocellular carcinoma [85]. In addition, miR-151 targets a putative metastasis suppressor, RhoGDIA, which leads to activation of Rac1, Cdc42 and Rho GTPases. Activation of this cascade induces cell mobility and spreading which stimulates the transformation of tumor metastasis and invasion [85].

More recently, using global miRNA expression profiling, Ding et al., identified that miR-375 is usually downregulated in gastric cancer as compared to adjacent non-tumor tissues [86]. Overexpression of miR-375 inhibited proliferation in both in vitro and in vivo studies of gastric cancer. The mechanism for the suppression in gastric cancer was further discussed when Janus kinase 2 (JAK2) was identified as a target of miR-375 [86]. Another cancerous inhibitor of PP2A (CIP2A), a guardian of the oncoprotein MYC, was also identified as a target for miR-375 by bioinformatic and experimental methods [87]. Overexpression of miR-375 caused reduction of the expression of CIP2A resulting in a decrease of MYC protein levels, in turn leading to reduced proliferation, colony formation, migration, and invasion in oral cancer cells. This suggested that miR-375 could act as a tumor suppressor and that a low expression level contributes to transforming the cancerous phenotype [87].

Using miRNA mimic screening and migration assay, Huang et al., found that miR-373 and miR-520c stimulate cancer cell migration and invasion in vitro and in vivo in breast cancer [88]. The migration activity has been suggested to be due to these miRNAs targeting CD44 for which expression correlations were found to be opposite [88]. Moreover, the miR-520/373 family inhibited NF-kB signaling by targeting RELA, leading to significantly reduced expression and secretion of the pro-inflammatory cytokines interleukin (IL)-6 and IL-8 [89]. Moreover, the miR-520/373 family suppressed transforming growth factor-b (TGF-b) signaling, Smad, plasminogen activator inhibitor-1, and angiopoietinlike 4 in vitro and in vivo [89]. Taken together, the miR520/373 family has a tumor-suppressive role and contributes to tumor progression and metastasis in breast cancer.

\section{CANCER REGULATORY NETWORKS}

As described in detail above, it has been possible to intimately link dysregulation of miRNA expression with many cancer types, cancer progression and invasiveness. Interestingly, many miRNAs are ambivalent in their regulative outcome. We attribute this to the fact that a single miRNA or gene product alone, may not suffice to explain a phenotype in cancer biology. We therefore suggest investigation of the intersection of gene and miRNA regulatory networks to achieve a more detailed and global view of cancer-related dysregulation. In the future, all these individual findings, as outlined above, must be viewed within the larger context of super regulatory networks.

\section{SUPER REGULATORY NETWORKS}

MicroRNAs can originate from genes or can come from their own transcription units. In any case, their mode of action is immediate, unlike genes which first have to be transcribed and translated before their product performs an action. Although it is at times beneficial to investigate local effects of expression changes, the results only provide significant benefits in the larger context of the suitable regulatory network. By extension, the same is true for regulatory networks which may be so intertwined that they cannot be treated separately. In line with this, Zhou and colleagues pointed out the importance of a combined miRNA and gene regulatory network, but acknowledged that, at times, it is beneficial to investigate the two networks independently [20]. On the other hand, many subnetworks may be redundant and can thus replace each other functionally and could be investigated separately. Even though all regulatory levels come together to achieve homeostasis, some key players may exist in the super regulatory network and influencing them may compromise homeostasis. However, the reconstruction of regulatory networks is a complex task.

\section{NETWORK RECONSTRUCTION}

The building of a gene or a miRNA regulatory network independently is not a trivial task and constructing a combined network is even more difficult. Li and colleagues used parallel miRNA and mRNA expression datasets from CellMiner [90], mirGen [91] for miRNA-gene relationships, and TRED [92] for transcription factor (TF) - gene relationships. From the combined data, they derived the TF-miRNA interactions using a number of assumptions and heuristics [93]. This seems to be the minimum amount of information needed to reconstruct a TF, gene, and miRNA network. Some caveats of this study are that some of the data seems to be outdated and could be enhanced with integrating information from competing databases and that no proteomics data is available and thus no proof on the protein level is possible.

In straightforward gene regulation, a gene leads to a product which then modulates the expression of other genes. However, Schlitt and Brazma argue that a gene product may not be able to achieve this regulation alone and must bind some other compound before. This involves a binding interaction; one among several types of relationship among the graph nodes (edge) that they were able to identify [15]. Another relationship that is not intuitive on a biological level is: 'has similar sequence', but for network reconstruction with unknown and known sequences, it may be useful to construct such interactions. Many other edges, such as biologically intuitive ones like 'activates', 'silences', and 'degrades', or computationally necessary ones like 'is cocited', 'is structurally similar', and 'provides evidence' constitute a reconstructed network.

A network pattern is a recurring subgraph and two wellknown regulatory patterns are feed-forward and feedback loops. For more information on network motifs please refer to [94]. Wingender and colleagues investigated which patterns concerning TF and miRNAs are present in different human tissues [95]. They were able to identify some common patterns (limited to three genes) but also regulatory motifs which are only found in subsets of tissue-specific recon- 
structed networks. Interestingly, they found that the more tissue specific motifs usually contain miRNAs whereas the common patterns usually do not. Concerning larger patterns, they found different bowtie structures noteworthy. Wingender and colleagues pointed out that most of the small motifs that they found represent feed-forward patterns [95] and it is interesting in this context to see that the oncomir miR-24-1 may be in a negative feedback loop [96]. Herranz and Cohen also described multiple uses of feedback motifs in nature [97]. In a large scale reconstruction, $\mathrm{Li}$ and colleagues found that only 5 of 18 possible small motifs consisting of one TF, one gene, and one miRNA significantly recurred in the network. Among these was only one feedback motif [93].

\section{DISCUSSION}

It is now clear that miRNA expression is closely associated with tumorigenicity, invasion and metastasis [98]. Wu further elaborates on the use of miRNAs as biomarkers, drugs, or drug enhancers [98]. Some new creative strategies of the use of miRNAs as drugs are miRNA mimics [99], multiple-target anti-miRNAs [100], and chemical inhibitors [101] as mentioned by [98]. The potential of miRNAs to function as drugs or drug targets is as broad as the spectrum of miRNA functions. This spectrum is huge since, according to recent estimates, up to $90 \%$ of human genes may be regulated by miRNAs [102]. We are currently establishing a full network of miRNAs and their targets in human and believe that the regulation is well beyond $100 \%$ which means that one or multiple miRNAs independently or synergistically regulate multiple human genes (Hamzeiy et al, in preparation).

The expression of many miRNAs is regulated by transcription factors while miRNAs reciprocally modulate the expression of many TFs. This fact establishes the link between miRNA and conventional gene regulatory networks. This link is difficult to establish in practice, but if a miRNA can be placed into a regulatory circuit, it becomes possible to understand its mode of action [97]. The miRNA and gene regulatory systems are designed to maintain robust function in face of external perturbations [103] and miRNAs strongly contribute to this robustness [104]. In addition to miRNA directed regulation and gene regulation, there are other ways for a cell to achieve homeostasis. For example, the half-life of any product directly influences its regulatory potential and the half-life can be dependent on the environment or on other stabilizing/ destabilizing molecules. Thus, any drugs targeting the complex interwoven regulatory network may have unexpected effects. In conclusion, these studies and combined network analysis tools can facilitate the investigation of short and long range effects upon the expression or function of gene products or miRNAs once proper super regulatory networks can be reconstituted.

\section{CONFLICT OF INTEREST}

The authors confirm that this article content has no conflicts of interest.

\section{ACKNOWLEDGEMENTS}

Part of this work has been supported by an award from the Turkish Academy of Sciences for outstanding young scientists (GEBIP, TUBA) received by JA. In addition, we also acknowledge the Swiss National Science Foundation (SNSF) for postdoctoral fellowship with grant PBZHP3 141430 and the Swiss Foundation for MedicalBiological (SFGBM) grant P3SMP3 148406 given to HVT. We would like to thank Prof. Dr. Anne Frary for proof reading the manuscript.

\section{REFERENCES}

[1] Ørom, U.A.; Nielsen, F.C.; Lund, A.H. MicroRNA-10a binds the 5'UTR of ribosomal protein mRNAs and enhances their translation. Mol. Cell, 2008, 30(4), 460-471.

[2] Vasudevan, S. Posttranscriptional upregulation by microRNAs. Wiley Interdiscip. Rev. RNA, 2011, 3(3), 311-330.

[3] Huang, V.; Place, R.F.; Portnoy, V.; Wang, J.; Qi, Z.; Jia, Z.; Yu, A.; Shuman, M.; Yu, J.; Li, L.C. Upregulation of Cyclin B1 by miRNA and its implications in cancer. Nucleic Acids Res., 2012, 40(4), 1695-1707.

[4] Vasudevan, S.; Tong, Y.; Steitz, J.A. Switching from repression to activation: microRNAs can up-regulate translation. Science, $\mathbf{2 0 0 7}$ 318(5858), 1931-1934.

[5] Mayr, M.; Zampetaki, A.; Willeit, P.; Willeit, J.; Kiechl, S. MicroRNAs within the continuum of postgenomics biomarker discovery. Arterioscler. Thromb. Vasc. Biol., 2013, 33(2), 206-214.

[6] Barrett, L.W.; Fletcher, S.; Wilton, S.D. Regulation of eukaryotic gene expression by the untranslated gene regions and other noncoding elements. Cell. Mol. Life Sci., 2012, 69(21), 3613-3634.

[7] Crick, F. Central dogma of molecular biology. Nature, 1970, 227(5258), 561-3.

[8] Wu, J.Y.; Tang, H.; Havlioglu, N. Alternative pre-mRNA splicing and regulation of programmed cell death. Prog. Mol. Subcell. Biol., 2003, 31(2), 153-85.

[9] Tanabe, M.; Kanehisa, M. Using the KEGG database resource. In: Curr. Protoc. Bioinformatics, 2012, vol. Chapter 1, p. Unit 1.12.

[10] Kanehisa, M.; Goto, S.; Sato, Y.; Furumichi, M.; Tanabe, M. KEGG for integration and interpretation of large-scale molecular data sets. Nucleic Acids Res., 2012, 40(Database issue), D109-14.

[11] D'Eustachio, P. Reactome knowledgebase of human biological pathways and processes. Methods Mol. Biol., 2011, 694, 49-61.

[12] Copeland, W.B.; Bartley, B.A.; Chandran, D.; Galdzicki, M.; Kim, K.H.; Sleight, S.C.; Maranas, C.D.; Sauro, H.M. Computational tools for metabolic engineering. Metab. Eng., 2012, 14(3), 270-80.

[13] Rohn, H.; Junker, A.; Hartmann, A.; Grafahrend-Belau, E.; Treutler, H.; Klapperstück, M.; Czauderna, T.; Klukas, C.; Schreiber, F. VANTED v2: A framework for systems biology applications. BMC Syst. Biol., 2012, 6(1), 139.

[14] Smoot, M.E.; Ono, K.; Ruscheinski, J.; Wang, P.-L.; Ideker, T. Cytoscape 2.8: new features for data integration and network visualization. Bioinformatics, 2011, 27(3), 431-432.

[15] Schlitt, T.; Brazma, A. Current approaches to gene regulatory network modelling. BMC Bioinformatics, 2007, 8(Suppl 6), S9.

[16] Geekiyanage, H.; Jicha, G.A.; Nelson, P.T.; Chan, C. Blood serum miRNA: non-invasive biomarkers for Alzheimer's disease. Exp. Neurol., 2012, 235(2), 491-496.

[17] Wang, F.; Sun, G.-P.; Zou, Y.-F.; Hao, J.-Q.; Zhong, F.; Ren, W.-J. MicroRNAs as promising biomarkers for gastric cancer. Cancer Biomark., 2012, 11(6), 259-267.

[18] Satoh, J.-I. Molecular network analysis of human microRNA targetome: from cancers to Alzheimer's disease. Bio Data Min., 2012, 5(1), 17.

[19] Emmrich, S.; Pützer, B.M. Checks and balances: E2F-microRNA crosstalk in cancer control. Cell Cycle, 2010, 9(13), 2555-2567.

[20] Zhang, S.; Li, Q.; Liu, J.; Zhou, X.J. A novel computational framework for simultaneous integration of multiple types of genomic data to identify microRNA-gene regulatory modules. Bioinformatics, 2011, 27(13), i401-409.

[21] Kent, O.A.; Mendell, J.T. A small piece in the cancer puzzle: microRNAs as tumor suppressors and oncogenes. Oncogene, $\mathbf{2 0 0 6}$, 25(46), 6188-6196.

[22] Garzon, R.; Calin, G.A.; Croce, C.M. MicroRNAs in Cancer. Annu. Rev. Med., 2009, 60, 167-179.

[23] Calin, G.A.; Dumitru, C.D.; Shimizu, M.; Bichi, R.; Zupo, S.; Noch, E.; Aldler, H.; Rattan, S.; Keating, M.; Rai, K.; Rassenti, L.; 
Kipps, T.; Negrini, M.; Bullrich, F.; Croce, C.M. Frequent deletions and down-regulation of micro- RNA genes miR15 and miR16 at 13q14 in chronic lymphocytic leukemia. Proc. Natl. Acad. Sci. USA, 2002, 99(24), 15524-15529.

[24] Nakamura, T.; Canaani, E.; Croce, C.M. Oncogenic All1 fusion proteins target Drosha-mediated microRNA processing. Proc. Natl. Acad. Sci. USA, 2007, 104(26), 10980-10985.

[25] Saito, Y.; Liang, G.; Egger, G.; Friedman, J.M.; Chuang, J.C.; Coetzee, G.A.; Jones, P.A. Specific activation of microRNA-127 with downregulation of the proto-oncogene BCL6 by chromatinmodifying drugs in human cancer cells. Cancer Cell, 2006, 9(6), 435-443.

[26] Calin, G.A.; Ferracin, M.; Cimmino, A.; Di Leva, G.; Shimizu, M.; Wojcik, S.E.; Iorio, M.V.; Visone, R.; Sever, N.I.; Fabbri, M.; Iuliano, R.; Palumbo, T.; Pichiorri, F.; Roldo, C.; Garzon, R.; Sevignani, C.; Rassenti, L.; Alder, H.; Volinia, S.; Liu, C.G.; Kipps, T.J.; Negrini, M.; Croce, C.M. A MicroRNA signature associated with prognosis and progression in chronic lymphocytic leukemia. N. Engl. J. Med., 2005, 353(17), 1793-1801.

[27] Cimmino, A.; Calin, G.A.; Fabbri, M.; Iorio, M.V.; Ferracin, M.; Shimizu, M.; Wojcik, S.E.; Aqeilan, R.I.; Zupo, S.; Dono, M.; Rassenti, L.; Alder, H.; Volinia, S.; Liu, C.G.; Kipps, T.J.; Negrini, M.; Croce, C.M. miR-15 and miR-16 induce apoptosis by targeting BCL2. Proc. Natl. Acad. Sci. USA, 2005, 102(39), 3944-13949.

[28] Raveche, E.S.; Salerno, E.; Scaglione, B.J.; Manohar, V.; Abbasi, F.; Lin, Y.C.; Fredrickson, T.; Landgraf, P.; Ramachandra, S.; Huppi, K.; Toro, J.R.; Zenger, V.E.; Metcalf, R.A.; Marti, G.E.; Abnormal microRNA-16 locus with synteny to human 13q14 linked to CLL in NZB mice. Blood, 2007, 109(12), 5079-5086.

[29] Iorio, M.V.; Ferracin, M.; Liu, C.G.; Veronese, A.; Spizzo, R.; Sabbioni, S.; Magri, E.; Pedriali, M.; Fabbri, M.; Campiglio, M.; Menard, S.; Palazzo, J.P.; Rosenberg, A.; Musiani, P.; Volinia, S.; Nenci, I.; Calin, G.A.; Querzoli, P.; Negrini, M.; Croce, C.M. MicroRNA gene expression deregulation in human breast cancer. Cancer Res., 2005, 65(16), 7065-7070.

[30] Johnson, S.M.; Grosshans, H.; Shingara, J.; Byrom, M.; Jarvis, R.; Cheng, A.; Labourier, E.; Reinert, K.L.; Brown, D.; Slack, F.J. RAS is regulated by the let-7 microRNA family. Cell, 2005, 120(5), 635-647.

[31] Yanaihara, N.; Caplen, N.; Bowman, E.; Seike, M.; Kumamoto, K.; Yi, M.; Stephens, R.M.; Okamoto, A.; Yokota, J.; Tanaka, T.; Calin, G.A.; Liu, C.G.; Croce, C.M.; Harris, C.C. Unique microRNA molecular profiles in lung cancer diagnosis and prognosis. Cancer Cell, 2006, 9(3), 189-198.

[32] Akao, Y.; Nakagawa, Y.; Naoe, T. let-7 microRNA functions as a potential growth suppressor in human colon cancer cells. Biol. Pharm. Bull., 2006, 29(5), 903-906.

[33] Lee, Y.S.; Dutta, A. The tumor suppressor microRNA let-7 represses the HMGA2 oncogene. Genes Dev., 2007, 21(9), 10251030.

[34] Sampson, V.B.; Rong, N.H.; Han, J.; Yang, Q.; Aris, V.; Soteropoulos, P.; Petrelli, N.J.; Dunn, S.P.; Krueger, L.J. MicroRNA let-7a down-regulates MYC and reverts MYC-induced growth in Burkitt lymphoma cells. Cancer Res., 2007, 67(20), 9762-9770.

[35] Pedersen-Bjergaard, J.; Pedersen, M.; Roulston, D.; Philip, P. Different genetic pathways in leukemogenesis for patients presenting with therapy-related myelodysplasia and therapy-related acute myeloid leukemia. Blood, 1995, 86(9), 3542-3552.

[36] Mott, J.L.; Kobayashi, S.; Bronk, S.F.; Gores, G.J. mir-29 regulates Mcl-1 protein expression and apoptosis. Oncogene, 2007, 26(42), 6133-6140.

[37] Pekarsky, Y.; Santanam, U.; Cimmino, A.; Palamarchuk, A.; Efanov, A.; Maximov, V.; Volinia, S.; Alder, H.; Liu, C.G.; Rassenti, L.; Calin, G.A.; Hagan, J.P.; Kipps, T.; Croce, C.M. Tcl1 expression in chronic lymphocytic leukemia is regulated by miR-29 and miR-181. Cancer Res., 2006, 66(24), 11590-11593.

[38] He, L.; Thomson, J.M.; Hemann, M.T.; Hernando-Monge, E.; Mu, D.; Goodson, S.; Powers, S.; Cordon-Cardo, C.; Lowe, S.W.; Hannon, G.J.; Hammond, S.M. A microRNA polycistron as a potential human oncogene. Nature, 2005, 435(7043), 828-833.

[39] Olive, V.; Bennett, M.J.; Walker, J.C.; Ma, C.; Jiang, I.; CordonCardo, C.; Li, Q.J; Lowe, S.W.; Hannon, G.J.; He, L. miR-19 is a key oncogenic component of mir-17-92. Genes Dev., 2009, 23(24), 2839-2849.
[40] Hong, L.; Lai, M.; Chen, M.; Xie, C.; Liao, R.; Kang, Y.J.; Xiao, C.; Hu, W.Y.; Han, J.; Sun, P. The miR-17-92 cluster of microRNAs confers tumorigenicity by inhibiting oncogene-induced senescence. Cancer Res., 2010, $70(21), 8547-8557$.

[41] Coller, H.A.; Forman, J.J.; Legesse-Miller, A. 'Myc'ed messages': myc induces transcription of E2F1 while inhibiting its translation via a microRNA polycistron. PLoS Genet., 2007, 3(8), e146.

[42] Hossain, A.; Kuo, M.T.; Saunders, G.F. Mir-17-5p regulates breast cancer cell proliferation by inhibiting translation of AIB1 mRNA. Mol. Cell Biol., 2006, 26(21), 8191-8201.

[43] Chan, J.A.; Krichevsky, A.M.; Kosik, K.S. MicroRNA-21 is an antiapoptotic factor in human glioblastoma cells. Cancer Res., 2005, 65(14), 6029-6033,

[44] Corsten, M.F.; Miranda, R.; Kasmieh, R.; Krichevsky, A.M.; Weissleder, R.; Shah, K. MicroRNA-21 knockdown disrupts glioma growth in vivo and displays synergistic cytotoxicity with neural precursor cell delivered S-TRAIL in human gliomas. Cancer Res., 2007, 67(19), 8994-9000.

[45] Papagiannakopoulos, T.; Shapiro, A.; Kosik, K.S. MicroRNA-21 targets a network of key tumor-suppressive pathways in glioblastoma cells. Cancer Res., 2008, 68(19), 8164-8172.

[46] Yao, Q.; Xu, H.; Zhang, Q.Q.; Zhou, H.; Qu, L.H. MicroRNA-21 promotes cell proliferation and down-regulates the expression of programmed cell death 4 (PDCD4) in HeLa cervical carcinoma cells. Biochem. Biophys. Res. Commun., 2009, 388(3), 539-542.

[47] Frankel, L.B.; Christoffersen, N.R.; Jacobsen, A.; Lindow, M.; Krogh, A.; Lund, A.H. Programmed cell death 4 (PDCD4) is an important functional target of the microRNA miR-21 in breast cancer cells. J. Biol. Chem., 2008, 283(2), 1026-1033.

[48] Becker B.L.E.; Li, Y. Apoptosis and the target genes of miR-21. Chin. J. Cancer., 2011, 30(6), 10.

[49] Esquela-Kerscher, A.; Slack, F.J. Oncomirs - microRNAs with a role in cancer. Nat. Rev. Cancer, 2006, 6(4), 259-269.

[50] Eis, P.S.; Tam, W.; Sun, L.; Chadburn, A.; Li, Z.; Gomez, M.F.; Lund, E.; Dahlberg, J.E. Accumulation of miR-155 and BIC RNA in human B cell lymphomas. Proc. Natl. Acad. Sci. USA, 2005, 102(10), 3627-3632.

[51] Costinean, S.; Sandhu, S.K.; Pedersen, I.M.; Tili, E.; Trotta, R.; Perrotti, D.; Ciarlariello, D.; Neviani, P.; Harb, J.; Kauffman, L.R.; Shidham, A.; Croce, C.M. Src homology 2 domain-containing inositol-5-phosphatase and CCAAT enhancer-binding protein beta are targeted by miR-155 in B cells of Emicro-MiR-155 transgenic mice. Blood, 2009, 114(7), 1374-1382.

[52] Chen, J.; Wang, B.C.; Tang, J.H. Clinical significance of microRNA-155 expression in human breast cancer. J. Surg. Oncol., 2012, 106(3), 260-266

[53] Davey, G.M.; Heath, W.R.; Starr, R. SOCS1: A potent and multifaceted regulator of cytokines and cell-mediated inflammation. Tissue Antigens, 2006, 67(1), 1-9.

[54] Jiang, S.; Zhang, H.W.; Lu, M.H.; He, X.H.; Li, Y.; Gu, H.; Liu, M.F.; Wang, E.D. MicroRNA-155 functions as an OncomiR in breast cancer by targeting the suppressor of cytokine signaling 1 gene. Cancer Res., 2010, 70(8), 3119-3127.

[55] Gironella, M.; Seux, M.; Xie, M.J.; Cano, C.; Tomasini, R.; Gommeaux, J.; Garcia, S.; Nowak, J.; Yeung, M.L.; Jeang, K.T.; Chaix, A.; Fazli, L.; Motoo, Y.; Wang, Q.; Rocchi, P.; Russo, A.; Gleave, M.; Dagorn, J.C.; Iovanna, J.L.; Carrier, A.; Pebusque, M.J.; Dusetti, N.J. Tumor protein 53-induced nuclear protein 1 expression is repressed by miR-155, and its restoration inhibits pancreatic tumor development. Proc. Natl. Acad. Sci. USA, 2007, 104(41), 16170-16175

[56] Greither, T.; Grochola, L.F.; Udelnow, A.; Lautenschlager, C.; Wurl, P.; Taubert, H. Elevated expression of microRNAs 155, 203 , 210 and 222 in pancreatic tumors is associated with poorer survival. Int. J. Cancer, 2010, 126(1), 73-80.

[57] Nikiforova, M.N.; Tseng, G.C.; Steward, D.; Diorio, D.; Nikiforov, Y.E. MicroRNA expression profiling of thyroid tumors: biological significance and diagnostic utility. J. Clin. Endocrinol. Metab., 2008, 93(5), 1600-1608.

[58] Ma, L.; Weinberg, R.A. Micromanagers of malignancy: Role of microRNAs in regulating metastasis. Trends Genet., 2008, 24(9), 448-456.

[59] Nicoloso, M.S.; Spizzo, R.; Shimizu, M.; Rossi, S.; Calin, G.A. MicroRNAs--the micro steering wheel of tumour metastases. Nat. Rev. Cancer, 2009, 9(4), 293-302. 
[60] Ma, L.; Teruya-Feldstein, J.; Weinberg, R.A. Tumour invasion and metastasis initiated by microRNA-10b in breast cancer. Nature, 2007, 449(7163), 682-688.

[61] Senyuk, V.; Zhang, Y.; Liu, Y.; Ming, M.; Premanand, K.; Zhou, L.; Chen, P.; Chen, J.; Rowley, J.D.; Nucifora, G.; Qian, Z. Critical role of miR-9 in myelopoiesis and EVI1-induced leukemogenesis. Proc. Natl. Acad. Sci. USA, 2013, 110(14), 5594-5599.

[62] Ma, L.; Young, J.; Prabhala, H.; Pan, E.; Mestdagh, P.; Muth, D.; Teruya-Feldstein, J.; Reinhardt, F.; Onder, T.T.; Valastyan, S.; Westermann, F.; Speleman, F.; Vandesompele, J.; Weinberg, R.A. miR-9, a MYC/MYCN-activated microRNA, regulates E-cadherin and cancer metastasis. Nat. Cell Biol., 2010, 12(3), 247-256.

[63] Hildebrandt, M.A.; Gu, J.; Lin, J.; Ye, Y.; Tan, W.; Tamboli, P.; C.; Wood, G.; Wu, X. Hsa-miR-9 methylation status is associated with cancer development and metastatic recurrence in patients with clear cell renal cell carcinoma. Oncogene, 2010, 29(42), 57245728.

[64] Lujambio, A.; Calin, G.A.; Villanueva, A.; Ropero, S.; SanchezCespedes, M.; Blanco, D.; Montuenga, L.M.; Rossi, S.; Nicoloso, M.S.; Faller, W.J.; Gallagher, W.M.; Eccles, S.A.; Croce, C.M.; Esteller, M. A microRNA DNA methylation signature for human cancer metastasis. Proc. Natl. Acad. Sci. USA, 2008, 105(36), 13556-13561.

[65] Tan, H.X.; Wang, Q.; Chen, L.Z.; Huang, X.H.; Chen, J.S.; Fu, X.H.; Cao, L.Q.; Chen, X.L.; Li, W.; Zhang, L.J. MicroRNA-9 reduces cell invasion and E-cadherin secretion in SK-Hep-1 cell. Med. Oncol., 2009, 27(3), 654-660.

[66] Nass, D.; Rosenwald, S.; Meiri, E.; Gilad, S.; Tabibian-Keissar, H.; A. Schlosberg, H. Kuker, N. Sion-Vardy, A. Tobar, O. Kharenko, Sitbon, E.; Lithwick Y.G.; Elyakim, E.; Cholakh, H.; Gibori, H.; Spector, Y.; Bentwich, Z.; Barshack, I.; Rosenfeld, N. MiR-92b and $\mathrm{miR}-9 / 9^{*}$ are specifically expressed in brain primary tumors and can be used to differentiate primary from metastatic brain tumors. Brain Pathol., 2009, 19(3), 375-383.

[67] Zhuang, G.; Wu, X.; Jiang, Z.; Kasman, I.; Yao, J.; Guan, Y.; Oeh, J.; Modrusan, Z.; Bais, C.; Sampath, D.; Ferrara, N. Tumoursecreted miR-9 promotes endothelial cell migration and angiogenesis by activating the JAK-STAT pathway. EMBO J., 2012, 31(17), 3513-3523.

[68] Baffa, R.; Fassan, M.; Volinia, S.; O’Hara, B.; Liu, C.G.; Palazzo, J.P.; Gardiman, M.; Rugge, M.; Gomella, L.G.; Croce, C.M.; Rosenberg, A. MicroRNA expression profiling of human metastatic cancers identifies cancer gene targets. J. Pathol., 2009, 219(2), 214-221.

[69] Bloomston, M.; Frankel, W.L.; Petrocca, F.; Volinia, S.; Alder, H.; Hagan, J.P.; Liu, C.G.; Bhatt, D.; Taccioli, C.; Croce, C.M. MicroRNA expression patterns to differentiate pancreatic adenocarcinoma from normal pancreas and chronic pancreatitis. JAMA, 2007, 297(17), 1901-1908.

[70] Chai, G.; Liu, N.; Ma, J.; Li, H.; Oblinger, J.L.; Prahalad, A.K.; Gong, M.; Chang, L.S.; Wallace, M.; Muir, D.; Guha, A.; Phipps, R.J.; Hock, J.M.; Yu, X. MicroRNA-10b regulates tumorigenesis in neurofibromatosis type 1. Cancer Sci., 2010,101(9), 1997-2004.

[71] Tian, Y.; Luo, A.; Cai, Y.; Su, Q.; Ding, F.; Chen, H.; Liu; Z. MicroRNA-10b promotes migration and invasion through KLF4 in human esophageal cancer cell lines. J. Biol. Chem., 2010, 285(11), 7986-7994.

[72] Li, G.; Wu, Z.; Peng, Y.; Liu, X.; Lu, J.; Wang, L.; Pan, Q.; He, M.L.; Li, X.P. MicroRNA-10b induced by Epstein-Barr virusencoded latent membrane protein-1 promotes the metastasis of human nasopharyngeal carcinoma cells. Cancer Lett., 2010, 299 (1), 29-36.

[73] Yamakuchi, M.; Lotterman, C.D.; Bao, C.; Hruban, R.H.; Karim, B.; Mendell, J.T.; Huso, D.; Lowenstein, C.J. P53-induced microRNA-107 inhibits HIF-1 and tumor angiogenesis. Proc. Natl. Acad. Sci. USA, 2010, 107(14), 6334-6339.

[74] Chen, H.Y.; Lin, Y.M.; Chung, H.C.; Lang, Y.D.; Lin, C.J.; Huang, J.; Wang, W.C.; Lin, F.M.; Chen, Z.; Huang, H.D.; Shyy, J.Y.; Liang, J.T.; Chen, R.H. miR-103/107 promote metastasis of colorectal cancer by targeting the metastasis suppressors DAPK and KLF4. Cancer Res., 2012, 72(14), 3631-3641.

[75] Martello, G.; Rosato, A.; Ferrari, F.; Manfrin, A.; Cordenonsi, M.; Dupont, S.; Enzo, E.; Guzzardo, V.; Rondina, M.; Spruce, T.; Parenti, A.R.; Daidone, M.G.; Bicciato, S.; Piccolo, S. A MicroRNA targeting dicer for metastasis control. Cell, 2010, 141(7), 1195-1207.
[76] Chen, P.S.; Su, J.L.; Cha, S.T.; Tarn, W.Y.; Wang, M.Y.; Hsu, H.C.; Lin, M.T.; Chu, C.Y.; Hua, K.T.; Chen, C.N.; Kuo, T.C.; Chang, K.J.; Hsiao, M.; Chang, Y.W.; Chen, J.S.; Yang, P.C.; Kuo, M.L. miR-107 promotes tumor progression by targeting the let-7 microRNA in mice and humans. J. Clin. Invest., 2011, 121(9), 3442-3455.

[77] Akao, Y.; Nakagawa, Y.; Kitade, Y.; Kinoshita, T.; Naoe, T. Downregulation of microRNAs-143 and -145 in B-cell malignancies. Cancer Sci., 2007, 98(12), 1914-1920.

[78] Takagi, T.; Iio, A.; Nakagawa, Y.; Naoe, T.; Tanigawa, N.; Akao, Y. Decreased expression of microRNA-143 and -145 in human gastric cancers. Oncology, 2009, 77(1), 12-21.

[79] Volinia, S.; Calin, G.A.; Liu, C.G.; Ambs, S.; Cimmino, A.; Petrocca, F.; Visone, R.; Iorio, M.; Roldo, C.; Ferracin, M.; Prueitt, R.L.; Yanaihara, N.; Lanza, G.; Scarpa, A.; Vecchione, A.; Negrini, M.; Harris, C.C.; Croce, C.M. A microRNA expression signature of human solid tumors defines cancer gene targets. Proc. Natl. Acad. Sci. USA, 2006, 103(7), 2257-2261.

[80] Borralho, P.M.; Simoes, A.E.; Gomes, S.E.; Lima, R.T.; Carvalho, T.; Ferreira, D.M.; Vasconcelos, M.H.; Castro, R.E.; Rodrigues, C.M. miR-143 overexpression impairs growth of human colon carcinoma xenografts in mice with induction of apoptosis and inhibition of proliferation. PLoS One, 2011, 6(8), e23787.

[81] Noguchi, S.; Mori, T.; Hoshino, Y.; Maruo, K.; Yamada, N.; Kitade, Y.; Naoe, T.; Akao, Y. MicroRNA-143 functions as a tumor suppressor in human bladder cancer T24 cells. Cancer Lett., 2011, 307(2), 211-220.

[82] Boettger, T.; Beetz, N.; Kostin, S.; Schneider, J.; Kruger, M.; Hein, L.; Braun, T. Acquisition of the contractile phenotype by murine arterial smooth muscle cells depends on the Mir143/145 gene cluster. J. Clin. Invest., 2009,119(9), 2634-2647.

[83] Chen, X.; Guo, X.; Zhang, H.; Xiang, Y.; Chen, J.; Yin, Y.; Cai, X.; Wang, K.; Wang, G.; Ba, Y.; Zhu, L.; Wang, J.; Yang, R.; Zhang, Y.; Ren, Z.; Zen, K.; Zhang, J.; Zhang, C.Y. Role of miR143 targeting KRAS in colorectal tumorigenesis. Oncogene, 2009, 28(10), 1385-1392.

[84] McLean, G.W.; Carragher, N.O.; Avizienyte, E.; Evans, J.; Brunton, V.G.; Frame, M.C. The role of focal-adhesion kinase in cancer - a new therapeutic opportunity. Nat. Rev. Cancer, 2005, $5(7), 505-515$.

[85] Ding, J.; Huang, S.; Wu, S.; Zhao, Y.; Liang, L.; Yan, M.; Ge, C.; Yao, J.; Chen, T.; Wan, D.; Wang, H.; Gu, J.; Yao, M.; Li, J.; Tu, H.; He, X. Gain of miR-151 on chromosome 8q24.3 facilitates tumour cell migration and spreading through downregulating RhoGDIA. Nat. Cell Biol., 2010, 12(4), 390-399.

[86] Ding, L.; Xu, Y.; Zhang, W.; Deng, Y.; Si, M.; Du, Y.; Yao, H.; Liu, X.; Ke, Y.; Si, J.; Zhou, T. MiR-375 frequently downregulated in gastric cancer inhibits cell proliferation by targeting JAK2. Cell Res., 2010, 20(7), 784-793.

[87] Jung, H.M.; Patel, R.S.; Phillips, B.L.; Wang, H.; Cohen, D.M.; Reinhold, W.C.; Chang, L.J.; Yang, L.J.; Chan, E.K. Tumor suppressor miR-375 regulates MYC expression via repression of CIP2A coding sequence through multiple miRNA-mRNA interaction. Mol. Biol. Cell, 2013, 24(11), 1638-1648.

[88] Huang, Q.; Gumireddy, K.; Schrier, M.; le Sage, C.; Nagel, R.; Nair, S.; Egan, D.A.; Li, A.; Huang, G.; Klein-Szanto, A.; Gimotty, J.; Katsaros, P.A.; Coukos, D.; Zhang, G.; Pure, L.E.; Agami, R. The microRNAs miR-373 and miR-520c promote tumour invasion and metastasis. Nat. Cell Biol., 2008, 10(2), 202-210.

[89] Keklikoglou, I.; Koerner, C.; Schmidt, C.; Zhang, J.D.; Heckmann, D.; Shavinskaya, A.; Allgayer, H.; Guckel, B.; Fehm, T.; Schneeweiss, A.; Sahin, O.; Wiemann, S.; Tschulena, U. MicroRNA-520/373 family functions as a tumor suppressor in estrogen receptor negative breast cancer by targeting NF-kappaB and TGF-beta signaling pathways. Oncogene, 2012, 31(37), 41504163.

[90] Reinhold, W.C.; Sunshine, M.; Liu, H.; Varma, S.; Kohn, K.W.; Morris, J.; Doroshow, J.; Pommier, Y. CellMiner: a web-based suite of genomic and pharmacologic tools to explore transcript and drug patterns in the NCI-60 cell line set. Cancer Res., 2012, 72(14), 3499-3511.

[91] Megraw, M.; Sethupathy, P.; Corda, B.; Hatzigeorgiou, A.G. miRGen: A database for the study of animal microRNA genomic organization and function. Nucleic Acids Res., 2007, 35(Database issue, D149-155. 
[92] Zhao, F.; Xuan, Z.; Liu, L.; Zhang, M.Q. TRED: A Transcriptional Regulatory Element Database and a platform for in silico gene regulation studies. Nucleic Acids Res., 2005, 33(Database issue), D103-7.

[93] Yu, H.; Tu, K.; Wang, Y.-J.; Mao, J.-Z.; Xie, L.; Li, Y.-Y.; Li, Y.$\mathrm{X}$. Combinatorial network of transcriptional regulation and microRNA regulation in human cancer. BMC Syst. Biol., 2012, 6, 61 .

[94] Alon, U. Network motifs: theory and experimental approaches. Nat. Rev. Genet., 2007, 8(6), 450-461.

[95] Li, J.; Hua, X.; Haubrock, M.; Wang, J.; Wingender, E. The architecture of the gene regulatory networks of different tissues. Bioinformatics, 2012, 28(18), i509-i514.

[96] Luzi, E.; Marini, F.; Giusti, F.; Galli, G.; Cavalli, L.; Brandi, M.L. The negative feedback-loop between the oncomir Mir-24-1 and menin modulates the Men1 tumorigenesis by mimicking the 'Knudson's second hit'. PLoS One, 2012, 7(6), e39767.

[97] Herranz, H.; Cohen, S.M. MicroRNAs and gene regulatory networks: managing the impact of noise in biological systems. Genes Dev., 2010, 24(13), 1339-1344.

Received: July 24, 2013

Revised: November 18, 201

Accepted: May 18, 2014
[98] Wu, W. MicroRNA: potential targets for the development of novel drugs?, Drugs R. D., 2010, $10(1), 1-8$

[99] Xiao, J.; Yang, B.; Lin, H.; Lu, Y.; Luo, X.; Wang, Z. Novel approaches for gene-specific interference via manipulating actions of microRNAs: Examination on the pacemaker channel genes HCN2 and HCN4. J. Cell. Physiol., 2007, 212(2), 285-292.

[100] Lu, Y.; Xiao, J.; Lin, H.; Bai, Y.; Luo, X.; Wang, Z.; Yang, B. A single anti-microRNA antisense oligodeoxyribonucleotide (AMO) targeting multiple microRNAs offers an improved approach for microRNA interference. Nucleic Acids Res., 2009, 37(3), e24.

[101] Gumireddy, K.; Young, D.D.; Xiong, X.; Hogenesch, J.B.; Huang, Q.; Deiters, A. Small-molecule inhibitors of microrna miR-21 function. Angew. Chem. Int. Ed. Engl., 2008, 47(39), 7482.

[102] Miranda, K.C.; Huynh, T.; Tay, Y.; Ang, Y.-S.; Tam, W.-L.; Thomson, A.M.; Lim, B.; Rigoutsos, I. A pattern-based method for the identification of MicroRNA binding sites and their corresponding heteroduplexes. Cell, 2006, 126(6), 1203-1217.

[103] Kitano, H. A robustness-based approach to systems-oriented drug design. Nat. Rev. Drug Discov., 2007, 6(3), 202-210.

[104] Ebert, M.S.; Sharp P.A. Roles for microRNAs in conferring robustness to biological processes. Cell, 2012, 149(3), 515-524. 